\title{
Allocution du Ministre des affaires culturelles du Québec, Monsieur Jean-Noël Tremblay
}

Jean-Noël Tremblay

Volume 23, numéro 1, juin 1969

URI : https://id.erudit.org/iderudit/302850ar

DOI : https://doi.org/10.7202/302850ar

Aller au sommaire du numéro

Éditeur(s)

Institut d'histoire de l'Amérique française

ISSN

0035-2357 (imprimé)

1492-1383 (numérique)

Découvrir la revue

Citer cet article

Tremblay, J.-N. (1969). Allocution du Ministre des affaires culturelles du Québec, Monsieur Jean-Noël Tremblay. Revue d'histoire de l'Amérique française, 23(1), 6-12. https://doi.org/10.7202/302850ar d'utilisation que vous pouvez consulter en ligne. 


\section{ALLOCUTION DU MINISTRE DES AFFAIRES CULTURELLES DU QUÉBEC MONSIEUR JEAN-NOËL TREMBLAY *}

Je n'ai pas la prétention de croire que le discours que je veux tenir devienne un jour un document d'archives qu'analyseront, scruteront, commenteront et interpréteront les patients chercheurs et les méticuleux historiens; je ne pense même pas qu'il soit digne qu'on en fasse une fiche. Aussi vous parlerai-je le plus simplement du monde de la relation entre l'histoire et la culture ou, si vous le voulez, plus dynamiquement, de la nécessité de l'histoire dans l'élaboration de la culture d'une nation.

Peut-être décèlerez-vous à travers mes propos certaine intention apologétique. Je ne m'en défendrai pas parce que je sais que, comme moi, vous êtes sensibles aux reproches qu'on nous fait et que, par le biais, on vous fait, de promouvoir, par votre travail, davantage les valeurs du passé que celles d'aujourd'hui et qu'il paraît à certains que vous montrez trop de complaisance pour le vieil héritage du passé quand vous devriez prendre votre part de la responsabilité exaltante de forger la "culture vivante".

C'est qu'on ne comprend pas que la culture, dans son sens le plus fort et le plus général, est, au plan statique comme au plan dynamique, l'ensemble des valeurs de la civilisation. Ce sont ces valeurs que vous exhumez, que vous classez, que vous manifestez par vos recherches et par vos écrits. Je ne prendrai pas partie dans les querelles toutes académiques qui divisent les tenants de l'histoire en deux écoles: celle qui veut que l'historien ne manifeste que les réalités du passé soigneusement inventoriées et cataloguées et l'autre qui lui assigne une vocation normative. Permettez que je vous dise qu'un profane se réjouit de l'existence de ces deux tendances qui lui valent d'avoir des

*Allocution prononcée au dîner annuel de l'Institut d'histoire de l'Amérique française, au Motel Neptune, Québec, le 17 mai 1969. 
ouvrages scientifiquement répertoriés et d'autres qui l'incitent à la réflexion en lui proposant des principes, des leçons et des règles de vie.

Ce n'est pas là un jugement de Salomon; c'est l'attitude d'un homme d'action, au surplus responsable pour une bonne part de l'épanouissement de la vie culturelle de notre nation. C'est du reste à ce titre que je vous parle ce soir et que je désire vous rendre hommage.

La tâche est facile si l'on songe aux mérites que vous avez et que vous vous êtes acquis par votre labeur. Et ce labeur, je le tiens pour essentiel dans la perspective de la sauvegarde et de l'expansion de notre patrimoine intellectuel. Penchés sur les documents, attelés à la tâche de la découverte et de l'écriture, vous rassemblez pour nous les pierres dispersées de l'édifice culturel qui permet de nous identifier à une culture originale et de retrouver les racines profondes de notre personnalité nationale. En nous ramenant aux sources vous nous montrez de quelle façon le rameau québécois est enté sur l'arbre millénaire de la culture française et vous nous faites bien voir que tous les surgeons qui en sont nés sont devenus à leur tour, dans un autre humus, nourris d'un autre suc, des arbres vigoureux qui, tout en conservant les caractères originaux du tronc qui les a engendrés, constituent aujourd'hui une variété nouvelle des arbres de l'espèce francophone.

Voilà une façon bien lyrique de dire à des spécialistes froids et rigoureux qu'ils sont les artisans les plus précieux de la conservation du patrimoine ! Mais au-delà des mots et des expressions, j'ai la conviction que vous me comprenez et que vous percevez les sentiments d'admiration que j'éprouve pour vous et pour votre œuvre.

Mais je ne voudrais pas que vous pensiez que je réduis votre importance et que je limite votre influence en vous enfermant dans la tour d'ivoire de vos cabinets de chercheurs. Il m'apparaît au contraire que l'exercice de votre métier a des vertus dynamiques, les plus fortes, les plus déterminantes. Car vous ne vous contentez pas de colliger des documents, de les collationner, d'en faire l'exégèse et de les réunir dans des ou- 
vrages savants à caractère hermétique ou ésotérique. Vous prolongez votre interrogation du passé en dégageant des lignes de force, des constantes, en tirant des leçons et, selon l'esprit qui vous anime et le rôle que vous vous assignez personnellement, vous tracez le chemin de l'avenir après avoir refait pour nous l'itinéraire du passé.

Vous nous rejoignez donc sur le chemin de l'actuel et vous donnez ainsi à votre démarche la dimension existentielle qui établit la continuité entre le passé et le présent, entre la tradition et l'évolution. Au fait, vous vous souciez fort peu de ceux qui veulent absolument faire une distinction entre la culture traditionnelle et la culture vivante. Votre fréquentation des auteurs, le contact avec les monuments du passé vous a depuis longtemps convaincus de cette vérité que la culture suit une courbe continue d'évolution, que les manifestations des civilisations ont des temps forts et des temps faibles et que l'histoire de l'humanité est faite de toutes les pulsations d'une vie qui ne s'est pas encore arrêtée. Vous administrez, de façon péremptoire, la preuve du phénomène de l'interaction des cultures et de l'interpénétration des civilisations.

C'est là, comme il me semble, l'aspect dynamique de vos recherches et de vos travaux. Vous mettez en effet à jour et, partant, à la disposition de tous un bien culturel qui devient le matériau de base dont se servent forcément les architectes des civilisations ou des cultures contemporaines. Vous laissez à ces derniers, pour peu qu'ils en aient le génie, l'idée, l'imagination et le talent, le soin de l'utiliser, de le transformer et de le sertir dans un assemblage qui traduit les préoccupations de notre époque et les perceptions de sa sensibilité.

Il n'y a donc pas de divorce entre ce que vous êtes et ce que sont ou veulent être les concepteurs ou créateurs de la culture vivante, il n'y a pas de point de rupture entre ce que vous faites et ce qu'ils font parce que dans ce domaine de la vie culturelle il n'y a pas de solution de continuité; il n'y en eut d'ailleurs jamais, et même si l'on allègue le fait des civilisations disparues, on n'est pas pour autant capable d'écarter cette réalité de l'influence de ces civilisations sur celles qui leur ont succédé. 
Ce que je vous dis là n'a que valeur et signification de lieu commun. Mais puisque je vous parle de la relation entre l'histoire et la culture, je sens le besoin de répondre à une objection - je devrais dire un reproche - qui m'est souvent faite, à savoir: que le ministre des Affaires culturelles s'intéresse plus au passé qu'au présent, qu'il se préoccupe davantage d'amasser ce qu'on appelle dédaigneusement des "cadavres" ou des "œuvres mortes" plutôt que de s'employer à "créer la culture vivante".

Je ne crois pas utile ici de faire un sort à cette accusation qui s'inspire d'une conception inexacte de la culture considérée, je l'ai dit plus haut, comme l'ensemble des valeurs de civilisation. Je dois toutefois rappeler qu'il y a lieu de distinguer entre la culture statique que je définis comme le monument ou l'assemblage de toutes les pierres qui font l'édifice culturel, et la culture dynamique ou l'influx qui, animant les individus qui assimilent et s'approprient les valeurs de civilisations, circule dans la société qu'elle vivifie, oxygène et regénère.

Ainsi, dans cette optique, il est essentiel que les pouvoirs publics tiennent compte de cette exigence de la circulation des valeurs culturelles dans la société. C'est pour satisfaire à cette exigence impérative que le ministère des Affaires culturelles axe toute son action sur la diffusion du bien culturel. Mais pour diffuser - c'est là une vérité de La Palice - il faut avoir quelque chose à diffuser; et ce quelque chose doit exister, il doit avoir été créé. D'où la relation nécessaire diffusion-création et création-diffusion.

Or, le bien culturel n'est pas simplement une denrée alimentaire. Il doit porter le sceau de la qualité et répondre aux besoins intellectuels du consommateur; il doit exister entre ce bien culturel et l'esprit qui le réclame une adéquation qui, en l'espèce, ne peut résider que dans un certain caractère, dans certaines qualités d'universalité. Il faut bien alors avoir recours d'abord à ce qu'il est convenu d'appeler des valeurs sûres, c'est-à-dire en pratique, à des œuvres qui ont subi l'épreuve du temps, à ces œuvres qu'on qualifie d'universelles précisément parce qu'elles expriment l'homme de tous les temps, de tous les milieux, ses 
inquiétudes, sa psychologie, ses aspirations et satisfont son appétit pour le vrai et le beau. Il n'est pas d'autre moyen pour cela que de puiser dans les trésors du passé, les plus lointains comme les plus proches de nous. Et si vous me permettez d'ouvrir une parenthèse, je dirai que cette utilisation des ressources du passé a une vertu exemplaire, qu'elle a une fonction didactique et qu'elle permet cette initiation nécessaire à l'éducation culturelle populaire. En effet, il ne faut pas oublier que, dans le domaine de l'éducation culturelle, il nous faut d'abord instruire, briser certaines résistances, déraciner des préjugés, apprivoiser un public souvent peu familier avec l'œuvre d'art, le tirer de certaines ornières et l'inciter à prendre contact avec des richesses culturelles dont il pense qu'elles sont nécessairement réservées à des élites ou à des coteries d'initiés.

A cet égard, je considère comme très important le travail de l'historien: historien de la politique, de l'économique, de la sociologie, de l'archéologie, de la littérature, des sciences, de la musique, de l'art, etc. J'estime d'autre part nécessaire de vulgariser les connaissances accumulées par tous ces historiens dont les travaux diffusés dans les écoles de tous les niveaux et par les programmes d'éducation des adultes familiariseront les citoyens avec les grandes richesses de la culture et des civilisations.

Ce que j'ai dit tantôt sur la nécessité de puiser dans les richesses du passé n'implique pas que l'effort de la diffusion doive se restreindre à cela. Il importe de poursuivre l'œuvre de création, de la stimuler, de l'encourager en invitant les créateurs, quel que soit le mode d'expression qu'ils aient choisi, à inventer, à produire, à enrichir le fonds des biens culturels en gardant cependant bien présente à l'esprit l'idée que l'œuvre ne dure que si elle porte la marque de l'universel, c'est-à-dire cette vérité, cette authenticité qui font que l'homme s'y retrouve, qu'il s'y voit comme en un miroir, et que l'artiste n'atteint un public et ne le conserve que s'il est capable de s'identifier à lui et de dire ce que les autres hommes pensent, voient et ressentent et qu'ils sont impuissants à exprimer eux-mêmes. On fait grand état aujourd'hui, dans tous les domaines de l'art, de l'expérimental, on s'efforce de dire l'indicible, on voudrait enfoncer la porte de 
la prison qui nous retient dans l'univers familier. Cela aboutit à des réussites étonnantes, à de grandes et mystérieuses créations, à des perceptions et à des sensations inconnues. C'est le signe du progrès, de l'évolution, du perfectionnement de l'homme et de l'élargissement des frontières de la culture et des civilisations. On éprouve l'irrépressible appétit de la nouveauté, le vertige des abîmes et l'incoercible attirance de l'inconnu.

Le temps permettra de faire le tri; le phénomène de la décantation dégagera l'or des scories. Les historiens feront plus tard un constat, rétabliront les valeurs; ils seront aidés dans leur tâche par les hommes qui n'auront retenu que les initiatives valables et productrices, abandonnant, négligeant et oubliant tout ce qui naît du snobisme, des modes fugitives, en somme toutes les œuvres qui, ne répondant pas à la notion de l'universel, n'auront mis en branle, à un moment donné que les mécanismes de la sensibilité épidermique.

Mesdames et messieurs les historiens, vous les témoins, les gardiens et les interprètes du passé, vous avez un rôle immense à jouer dans l'élaboration de la culture de notre nation. En nous ramenant aux origines de notre culture, en exhumant les richesses des civilisations, en amassant les pièces de l'histoire, en racontant la geste de l'humanité et celle de notre peuple, vous consolidez les assises de la culture vivante, vous infléchissez dans une large mesure la courbe de l'évolution de notre société et vous posez des jalons pour l'avenir de notre civilisation.

Le ministère des Affaires culturelles s'intéresse à vos travaux. Et qu'il me soit permis de vous dire que je n'hésite jamais à donner priorité aux recherches que vous poursuivez. C'est du reste pour cette raison que nous avons voulu aider l'Institut d'histoire de l'Amérique française; nous sommes toujours dans les mêmes dispositions, et je souhaite que s'établisse entre votre organisme et le ministère une collaboration encore plus étroite qui nous permette de mettre ensemble au point un programme de publications qui prolongeront le rayonnement de votre Institut et manifesteront davantage la nécessité et la qualité d'une entreprise encore trop peu connue et appréciée au Québec. 
Comme vous l'avez sans doute appris, nous avons créé cette année au ministère des Affaires culturelles l'Institut national de la civilisation dont la vocation est de conserver, d'enrichir et de faire connaître le patrimoine national. Dans le même esprit, je me propose de déposer, avant l'ajournement des travaux parlementaires, une loi-cadre dite "loi du patrimoine national" dont le but est de régir l'administration et le fonctionnement des musées, de préparer la création des musées régionaux, de créer les mécanismes de coordination avec la $\mathrm{BN}$, de regrouper les sociétés d'histoire régionale, de coordonner l'activité des autres, de doter le Québec d'une véritable loi des Archives, de faire l'inventaire et de protéger les sites archéologiques, les lieux et monuments historiques, les œuvres d'art, de favoriser l'étude et l'utilisation du folklore et de l'art traditionnel; bref, de regrouper et d'institutionnaliser tous les organismes gouvernementaux et para-gouvernementaux qui ont mission de veiller à la conservation et à la manifestation de l'héritage national. Inutile d'ajouter que nous aurons besoin de vous et que le projet de loi sera soumis à l'examen de tous ceux qui, depuis longtemps, œuvrent souvent seuls et sans moyens dans les divers domaines que je viens d'indiquer.

Monsieur le Président, il me reste à vous remercier de m'avoir invité et de m'avoir accueilli avec chaleur et cordialité. Veuillez croire que le Gouvernement du Québec et son ministère des Affaires culturelles apprécient vos efforts, votre travail persévérant et qu'ils vous savent gré de travailler avec nous à l'affirmation de l'identité québécoise.

Mesdames et Messieurs, je vous remercie de m'avoir écouté et de me donner, par votre présence à cette réunion de l'Institut d'histoire de l'Amérique française, l'assurance que l'œuvre admirable du chanoine Groulx se poursuit et que, forts de son exemple, vous continuez de croire qu'il n'y a rien qui puisse prévaloir contre le droit à la vie d'une nation.

JEAN-NoËL TREMBLAY

Ministre des Affaires culturelles du Québec 